\title{
A computational model to explore the role of angiogenic impairment on endochondral ossification during fracture healing
}

\author{
Adam OReilly · Kurt D. Hankenson · Daniel J. Kelly
}

Received: date / Accepted: date

\begin{abstract}
While it is well established that an adequate blood supply is critical to successful bone regeneration, it remains poorly understood how progenitor cell fate is affected by the altered conditions present in fractures with disrupted vasculature. In this study, computational models were used to explore how angiogenic impairment impacts oxygen availability within a fracture callus and hence regulates mesenchymal stem cell (MSC) differentiation and bone regeneration. Tissue differentiation was predicted using a previously developed algorithm which assumed that MSC fate is governed by the local oxygen tension and substrate stiffness. This was updated to include conditions for oxygen regu-
\end{abstract}

\section{Adam O'Reilly}

Trinity Centre for Bioengineering, Trinity Biomedical Sciences, Trinity College Dublin, Dublin, Ireland

Department of Mechanical and Manufacturing Engineering, School of Engineering, Trinity College Dublin, Dublin, Ireland

Tel.: +353-1-8964214

E-mail: oreillad@tcd.ie

Kurt D. Hankenson

Department of Clinical Studies New Bolton Centre, School of Veterinary Medicine, University of Pennsylvania, Philadelphia, Pennsylvania.

Department of Orthopaedic Surgery, Perelman School of Medicine, University of Pennsylvania, Philadelphia, Pennsylvania

Tel.: 517-355-1697

E-mail:kdhank@msu.edu

Daniel J. Kelly

Trinity Centre for Bioengineering, Trinity Biomedical Sciences, Trinity College Dublin, Dublin, Ireland.

Department of Mechanical and Manufacturing Engineering, School of Engineering, Trinity College Dublin, Dublin, Ireland.

Advanced Materials and Bioengineering Research Centre (AMBER), Royal College of Surgeons in Ireland and Trinity College Dublin, Dublin, Ireland.

Tel.: +353-1-8964214

Fax.: +353-1-6795554

E-mail: kellyd9@tcd.ie lated cell death and endochondral ossification. The updated algorithm was validated by using it within a model of normal fracture healing where it predicted the experimentally observed quantity and spatial distribution of bone and cartilage at 10 and 20 days post fracture (dpf). Furthermore, it also predicted the ratio of cartilage which had become hypertrophic at $10 \mathrm{dpf}$. Following this, three models of fracture healing with increasing levels of angiogenic impairment were developed. Under mild impairment the model predicted the experimentally observed reduction in hypertrophic cartilage at $10 \mathrm{dpf}$ as well as the persistence of cartilage at $20 \mathrm{dpf}$. Models of more severe angiogenic impairment predicted the development of fibrous and necrotic tissue within the callus. These results provide insight into how environmental factors specific to an ischemic callus regulate tissue regeneration and provide support for the hypothesis that endochondral ossification during fracture healing is governed by the local oxygen tension.

Keywords stem cell differentiation - finite element analysis · fracture healing - endochondral ossification · ischemic fracture healing

\section{Introduction}

Disruption of the blood supply during fracture healing of long bones has been shown to lead to complications such as delayed healing or non-union (Brinker, Mark R. and Bailey, Daniel E. Jr, 1997). Ischemic fractures are typically characterised by an altered temporal and spatial distribution of tissue phenotypes within the callus when compared to nonischemic fractures (Miedel et al, 2013; Lu et al, 2007). Observations range from increased cell apoptosis, reduced cell proliferation and decreased bone formation (Lu et al, 2007), to the persistence of cartilage within the ischemic fracture 
callus (Miedel et al, 2013). Similarly, knockout mouse models which lead to impaired angiogenesis (e.g. GPCR Kinase 2 Interacting Protein-1 (GIT1) knock out mice) have demonstrated a persistence of cartilaginous matrix within the fracture callus, which correlated with decreased blood vessel volume, number and connection density (Yin et al, 2014). Despite such studies, it remains unclear exactly how impaired angiogenesis and subsequent changes in the microenvironment of the fracture callus regulates MSC fate, and specifically MSC chondrogenesis, chondrocyte hypertrophy and the subsequent process of endochondral ossification.

In-silico models of MSC differentiation have long been used to better understand how environmental factors, and in particular mechanical cues, regulate tissue differentiation during fracture healing (Burke and Kelly, 2012; Burke et al, 2013; Checa and Prendergast, 2009; Lacroix et al, 2002; Lacroix and Prendergast, 2002; Isaksson et al, 2008; Alierta et al, 2014). We have previously used such computational models to provide support for the hypothesis that stem cell fate during fracture healing is governed by the local oxygen concentration and stiffness of the surrounding substrate (Burke and Kelly, 2012; Burke et al, 2013, 2014). This algorithm was developed based on in-vitro observations which demonstrate the fundamental role played by substrate stiffness in regulating MSC lineage commitment (Engler et al, 2006; Huebsch et al, 2010; Young et al, 2013; Park et al, 2011), and by experiments demonstrating that hypoxia inhibits osteogenesis and adipogenesis while promoting chondrogenesis (Kanichai et al, 2008; Cao, 2007; Hankenson et al, 2011; Peiffer et al, 2011; Hirao et al, 2006; Street et al, 2002; Gomillion and Burg, 2006; Hausman and Richardson, 2004). This computational model did not however propose a specific hypothesis for how environmental factors regulate the initiation and progression of chondrocyte hypertrophy and endochondral ossification, which is central to successful secondary fracture healing. This is clearly a potential limitation of such models, as a number of recent studies have demonstrated that low oxygen conditions can supress hypertrophy and endochondral ossification of chondrogenically primed MSCs (Zhu et al, 2014; Sheehy et al, 2012; Gawlitta et al, 2012; Leijten et al, 2012, 2014).

The goal of the current study was thus to use a computational mechanobiological model to test the hypothesis that the local oxygen tension regulates hypertrophy and endochondral ossification of the cartilaginous matrix that forms in the callus of a fractured long bone. Motivated by in-vitro observations (Zhu et al, 2014; Sheehy et al, 2012; Gawlitta et al, 2012; Leijten et al, 2012, 2014) our previous in-silico model of MSC differentiation (Burke and Kelly, 2012) was updated to include specific rules for how oxygen levels regulate hypertrophy of chondrocytes. The model was then tested by attempting to simulate fracture healing within a murine tibia in both normal and ischemic limbs, where experimental data was generated to quantify the proportion of hypertrophic cartilage within the calluses of such bones at specific time-points after the initiation of injury. Three different models of impaired angiogenesis (mild, moderate and severe) were developed and model predictions were compared to experimental observations of fracture healing in ischemic limbs and other models of reduced angiogenesis. Each model was constructed based on the hypothesis that ischemia arises as a result of delayed and reduced vascular ingrowth from the surrounding tissues.

\section{Materials \& Methods}

\subsection{Experimental Models of Fracture Healing to be Simulated}

Computational mechanobiological models of fracture healing under normal and impaired angiogenesis were developed and compared to experimental murine models of normal and ischemic fracture healing described in detail elsewhere (Taylor et al, 2009; Miedel et al, 2013). Briefly, for normal fracture healing, closed transverse fractures were created in both the right and left tibiae of 9 to 10 week-old mice. After this, using a hypodermic needle, a hole was bored in the cortex of the medial aspect of the tibial tuberosity through which a sterile 0.009-in-diameter, stainless steel pin was inserted the full length of the tibia until resistance was felt. This pin provided stability to the fracture site while tape splints provided initial rotational stability for the first 48 hours. At harvest, right tibias were dissected, intramedullary pins removed and tissues stored for subsequent histological analysis. Histological sections stained with safranin-O were used to differentiate between the total callus area, cartilaginous area and woven bone area. For the ischemic case the stabilised fracture was created in the left tibia in the same way as for the normal case, however before this procedure the left femoral artery and its branches between the inguinal ligament and saphenous/popliteal bifurcation were separated and removed.

\subsection{Finite Element Model}

A 3D Finite Element (FE) model of the fracture callus was constructed to determine the biophysical stimuli generated by loading of the callus during gait (Table 1). Full details of the dimensions and material properties (Figure 4A and Table 2) are available elsewhere (Burke et al, 2013). To simulate weight bearing, an axial ramp load was applied over 0.5 $\mathrm{s}$ at the top of the cortical shaft. The maximum applied loading of an intact mouse tibia has been approximated as $1.2 \mathrm{~N}$ (Prasad et al, 2010). It was assumed that the intramedullary pin supported $30 \%$ of this load. It was also assumed that 


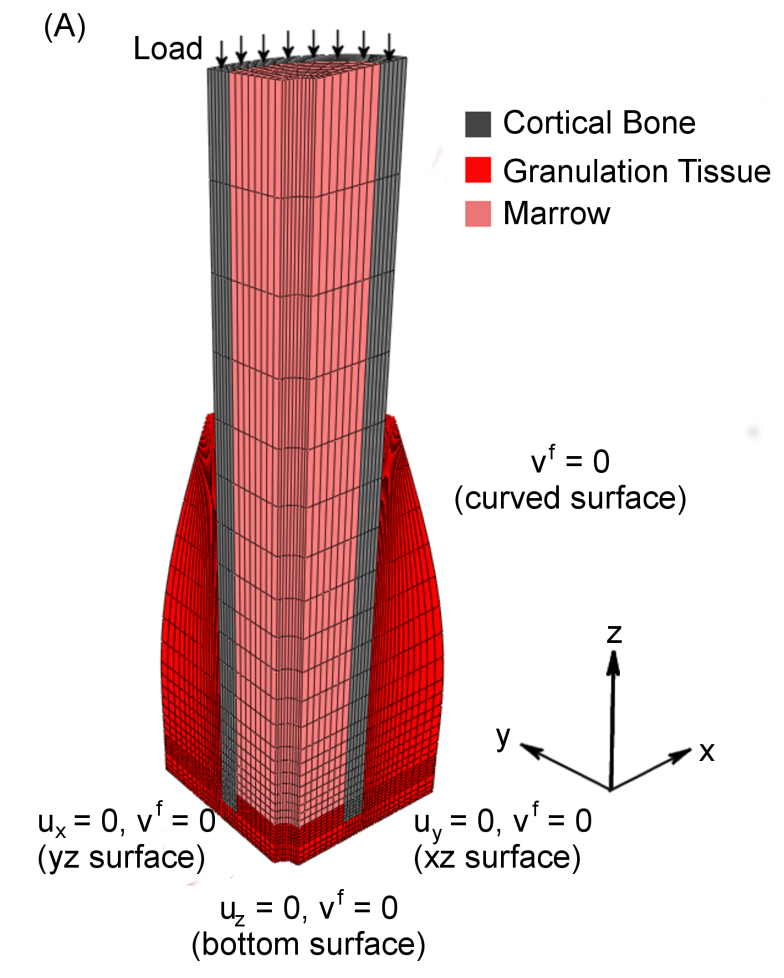

(B)
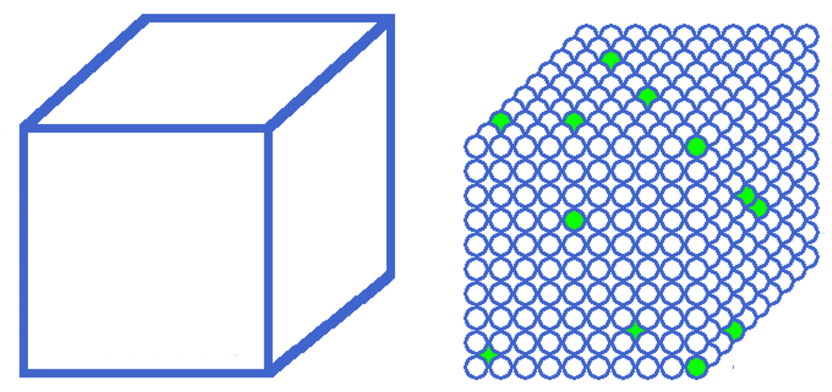

Filled Cell Position

Empty Cell Position

Fig. 1 (A) FE Model of the fracture callus. Loading is applied at the top of the cortical bone. Displacement and fluid velocity boundary conditions are shown as $\mathrm{u}$ and $\mathrm{vf}$ respectively. (B) A 3-dimensional finite element with corresponding lattice. Each lattice point represents a potential location for a cell.

Table 1 Dimensions of Finite Element Model (Burke et al, 2013)

\begin{tabular}{ll}
\hline Dimension & Measurement \\
\hline Callus Length & $6.33 \mathrm{~mm}$ \\
Callus Max Radius & $1.365 \mathrm{~mm}$ \\
Cortex Radius & $0.68 \mathrm{~mm}$ \\
Cortex Width & $0.17 \mathrm{~mm}$ \\
Pin Radius & $0.11 \mathrm{~mm}$ \\
Fracture Gap & $0.17 \mathrm{~mm}$
\end{tabular}

the callus was initially filled only with granulation tissue. At the end of each iteration, the material properties in the FE model were updated based on the results of the cell differentiation algorithm described below. The new parameters were calculated using a rule of mixtures in conjunction with a temporal smoothing procedure (Burke and Kelly, 2012). The described model was implemented in the open source finite element package FEBio (version 2.0, University of Utah, Technology Commercialization Office, 615 Arapeen Drive, Suite 310, Salt Lake City).

\subsection{Model of Angiogenesis}

Angiogenesis was modelled using a lattice based approach whereby the elements of the FE model was discretised into a sequence of lattice points, each of which represented a potential cell space (Figure 1B) (Checa and Prendergast, 2009). Each lattice point had a diameter of $10 \mu \mathrm{m}$ which corresponded with an overall lattice density of $1 \times 10^{6}$ lattice points $/ \mathrm{mm}^{3}$. Angiogenesis was then modelled as a sequence of adjoining lattice points, each of which represented an endothelial cell (EC) within a microvessel. Vessels were programmed to stop growing if the octahedral shear strain in the element exceeded a threshold limit $\left(\varepsilon^{\text {angio }}\right)$. If two vessels crossed the same path, anastomosis occurred and the two vessels fused together. Vessels were also able to branch should the vessel length exceed a certain value $\left(L^{\mathrm{min}}\right)$. The probability of branching then increased linearly until the vessel reached the maximum allowable length $\left(L^{\text {max }}\right)$ at which point the probability of branching occurring was 1 (Checa and Prendergast 2009).

Vessels grew at a constant rate $\left(V^{\text {growth }}\right)$ and could grow into any neighbouring lattice point provided that it was empty. Vessel direction was governed using the strain dependent rules proposed by Burke et al. (Burke, 2013). Briefly, there were three potential options which determined the vessel direction; 1) continue growing in the previous direction; 2) move in the direction of minimum principle strain or; 3 ) move in a random direction. The probability that a vessel would continue to grow in the same direction as the previous iteration $\left(P^{\text {prev }}\right)$ was 0.4 . The probability that a vessel 
Table 2 Material Properties

\begin{tabular}{|c|c|c|c|c|c|c|c|}
\hline Material Property & $\begin{array}{l}\text { Granulation } \\
\text { Tissue }\end{array}$ & $\begin{array}{l}\text { Fibrous } \\
\text { Tissue }\end{array}$ & Cartilage & $\begin{array}{l}\text { Hypertrophic } \\
\text { Cartilage }\end{array}$ & Marrow & $\begin{array}{l}\text { Immature } \\
\text { Bone }\end{array}$ & $\begin{array}{l}\text { Cortical } \\
\text { Bone }\end{array}$ \\
\hline Young's Modulus [MPa] & $1^{\mathrm{a}}$ & $2^{\mathrm{a}, \mathrm{b}}$ & $10^{\mathrm{a}}$ & 10 & 0.1 & $1000^{\mathrm{a}}$ & $20,000^{c}$ \\
\hline Poisson's Ratio & $0.167^{\mathrm{a}}$ & $0.167^{\mathrm{a}}$ & $0.167^{\mathrm{a}}$ & 0.167 & $0.167^{\mathrm{d}}$ & $0.3^{\mathrm{a}}$ & $0.3^{\mathrm{a}}$ \\
\hline Permeability $\left[\mathrm{mm}^{4} \mathrm{Ns}^{-1}\right]$ & $0.01^{\mathrm{a}}$ & $0.01^{\mathrm{a}}$ & $0.001^{\mathrm{a}}$ & 0.001 & $0.01^{\mathrm{d}}$ & $0.1^{\mathrm{a}}$ & $0.00001^{\mathrm{a}}$ \\
\hline Solid Volume Fraction & $0.2^{\mathrm{a}}$ & $0.2^{\mathrm{a}}$ & $0.2^{\mathrm{a}}$ & 0.2 & $0.2^{\mathrm{d}}$ & $0.2^{\mathrm{a}}$ & $0.2^{\mathrm{a}}$ \\
\hline
\end{tabular}

${ }^{\mathrm{a}}$ Lacroix et al (2002)

b Hori and Lewis (1982)

c Claes et al (1998)

${ }^{\mathrm{d}}$ Burke et al (2013)

would grow in the direction of the minimum principle strain $\left(P^{\text {strain }}\right)$ was dependent upon the magnitude of the strain; this was calculated using a simple linear model where $P^{\text {strain }}=0$ at $\varepsilon^{\text {min }}=0$ up to maximum of $P^{\text {strain }}=0.6$ at $\varepsilon^{\min } \min 0.18$. The final case where a vessel grew in a random direction was dictated by the remaining probability $\left(1-P^{\text {prev }}-P^{\text {strain }}\right)$.

\subsection{Cell Migration, Cell Proliferation and Cell Death}

The migration and proliferation of MSCs, osteoblasts (OBs), adipocytes (ABs), chondrocytes (CCs), hypertrophic chondrocytes (HCs) and fibroblasts (FBs) was also modelled using the lattice approach (Pérez and Prendergast, 2007; Checa and Prendergast, 2009). The migration of cells was implemented using random walk theory where a cell attempted to randomly move into any of its neighbouring lattice points (Pérez and Prendergast, 2007). If the decided upon position already contained a cell however, then that cell remained where it was and the migration process terminated for that iteration. Cell proliferation was implemented in a similar fashion provided that there was a vacant position beside the parent cell, i.e. it would proliferate and the newly formed daughter cell would occupy the empty space. If there was no empty space available then the cell did not proliferate (contact inhibition). Based on in-vitro studies examining MSC activity in low oxygen environments, proliferation was inhibited should the oxygen concentration fall below a threshold value $\left(\mathrm{O}_{2}{ }^{\text {prolif }}\right)$ (Zhu et al, 2006). Proliferation was also inhibited if the cell density within an element exceeded $1 \mathrm{x}$ $10^{5}$ cells $/ \mathrm{mm}^{3}$ (Burke and Kelly, 2012). The migration rate $(M)$ determined the number of attempted migration actions per time step while the doubling time $(D T)$ was the time which had to have elapsed before a cell proliferated (Table 4). In accordance with previous studies, $3 \%$ of the lattice points along the assigned boundaries (Figure 3B) and 0.05 $\%$ of the interior lattice points contained MSCs at the start of the simulation. Finally, if the oxygen concentration fell below $\mathrm{O}_{2}{ }^{\text {death }}$ then cell death was initiated where the rate of cell death was governed by the parameter $Q^{\text {death }}$ (Table 4).
Necrotic cells remained within the lattice for 4 iterations before they were assumed to be removed by immune cells.

\subsection{Oxygen Transport}

Oxygen transport was modelled using the FE package COMSOL Multiphysics (version 4.3). The governing equation (Equation 1) was updated during each iteration based on the average number of each cell type in a specific element as well as the degree of vascularity.

$\frac{d O_{2}}{d t}=G \nabla^{2} O_{2}-\sum_{n=1}^{6} \rho^{n} \frac{Q^{\max , n}}{K^{m, n}+O_{2}}$

The oxygen diffusion coefficient $\mathrm{G}=2.2 \times 10^{-3} \mathrm{~mm}^{2} \mathrm{~s}^{-1}$. Oxygen consumption was modelled separately for each cell phenotype using Michealas-Menten kinetics. In the equation each phenotype was represented by $n$, whereby $n=1$ represented MSCs; $n=2$ represented CCs; $n=3$ represented OBs; $n=4$ represented FBs; $n=5$ represented $\mathrm{AB}$ and; $n=6$ represented HCs (Table 5). For each cell type; n was the number of cells in the element; Qmax,n was the maximum oxygen consumption and; $K_{m, n}$ was the oxygen consumption at half maximum concentration. The oxygen boundary conditions were updated based on the percentage of lattice points in each element which contained blood vessels ( $\left.v^{\text {density }}\right)$. If $v^{\text {density }}>0$ the oxygen concentration increased linearly up to a maximum concentration of $101.6 \times 10-12 \mathrm{~mol} / \mathrm{mm}^{3}$ at a $v^{\text {density, } \max }$ of $8 \%$.

\subsection{MSC Differentiation and Hypertrophy}

The rules governing MSC differentiation are outlined in detail elsewhere (Figure 2A) (Burke and Kelly, 2012). Briefly, in regions of hypoxia $\left(\mathrm{O}_{2} \leq \mathrm{O}_{2}{ }^{\text {cartilage }}\right)$ MSCs differentiated into chondrocytes. In regions of normoxia $\left(\mathrm{O}_{2}>\mathrm{O}_{2}{ }^{\text {cartilage }}\right)$ MSCs could differentiate into $\mathrm{OBs}$, $\mathrm{ABs}$ or $\mathrm{FBs}$ depending on the substrate stiffness. A high substrate stiffness promoted osteogenesis while low substrate stiffness promoted 
(A)

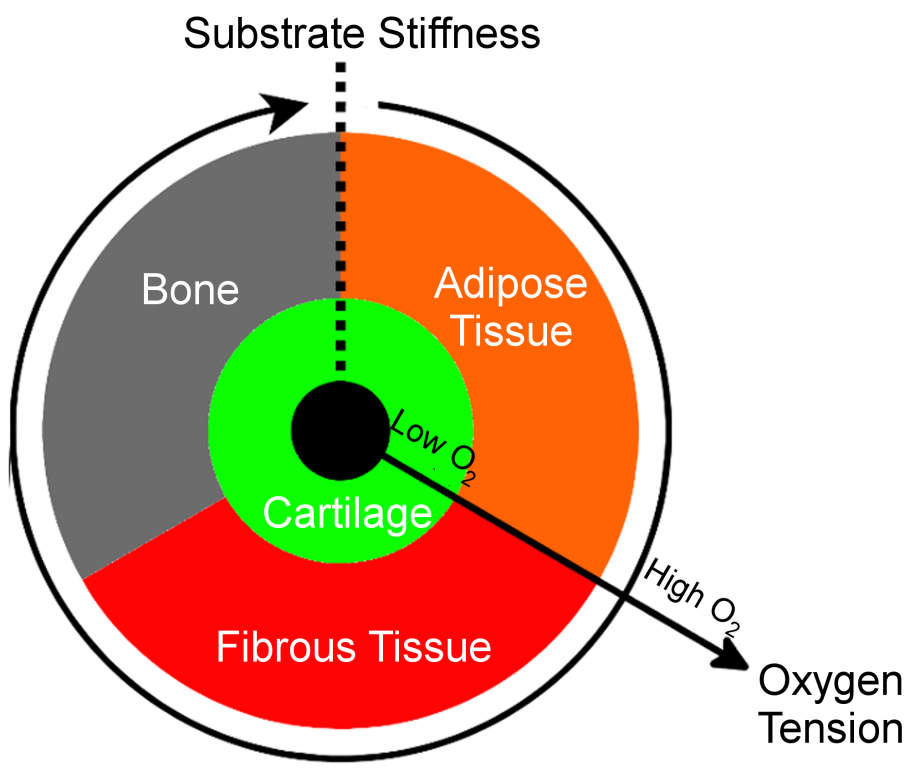

(B)

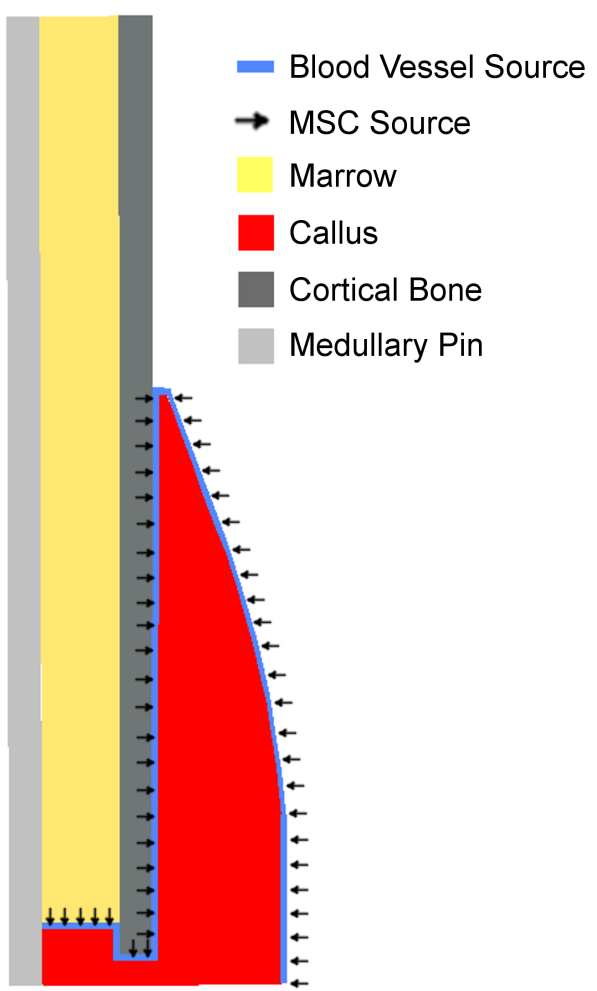

Fig. 2 (A) Tissue differentiation regulated by substrate stiffness and oxygen availability. The oxygen availability axis extends radially from the centre of the circle with low oxygen in the centre and increasing towards the periphery. The substrate stiffness axis extends circumferentially in a clockwise direction from the right side of the dotted line at the top of the circle. (B) Geometry and boundary conditions of the fracture callus.

Table 3 Tissue Differentiation Model Parameters

\begin{tabular}{|c|c|c|c|c|c|}
\hline Model Parameter & Symbol & \multicolumn{2}{|l|}{ Source } & Unit & Value \\
\hline $\begin{array}{l}\text { Strain threshold for inhibition of angio- } \\
\text { genesis }\end{array}$ & $\varepsilon^{\text {angio }}$ & \multicolumn{2}{|l|}{ Estimated } & $\%$ & 9 \\
\hline Blood vessel growth rate & $\mathrm{V}$ & \multicolumn{2}{|l|}{ Estimated } & $\mathrm{mm}(1 / 2 \text { day })^{-1}$ & 0.03 \\
\hline Minimum length for branching & $\mathrm{L}^{\mathrm{min}}$ & $\begin{array}{l}\text { Checa and } \\
(2009)\end{array}$ & Prendergast & $\mathrm{mm}$ & 0.2 \\
\hline Minimum length without branching & $\mathrm{L}^{\max }$ & $\begin{array}{l}\text { Checa and } \\
(2009)\end{array}$ & Prendergast & $\mathrm{mm}$ & 0.5 \\
\hline Minimum age for cell differentiation & Age $^{\text {diff }}$ & \multicolumn{2}{|l|}{ Estimated } & days & 2.5 \\
\hline Oxygen diffusion coefficient & $\mathrm{G}$ & \multicolumn{2}{|c|}{$\begin{array}{l}\text { Hershey and Karhan (1968); } \\
\text { Burke and Kelly (2012) }\end{array}$} & $\mathrm{mm}^{2} \mathrm{~s}^{-1}$ & $2.2 \mathrm{E}-03$ \\
\hline Initial oxygen tension & $\mathrm{O}_{2}{ }^{\text {initial }}$ & \multicolumn{2}{|c|}{ Epari et al (2008) } & $\mathrm{mol} \mathrm{mm} \mathrm{m}^{-3}$ & $101.6 \mathrm{E}-12$ \\
\hline Oxygen limit for cartilage & $\mathrm{O}_{2}$ cartilage & \multicolumn{2}{|c|}{ Burke and Kelly (2012) } & $\mathrm{mol} \mathrm{mm}^{-3}$ & $30.48 \mathrm{E}-12$ \\
\hline Oxygen limit for ccell death & $\mathrm{O}_{2}$ death & \multicolumn{2}{|c|}{ Zhu et al (2006) } & $\mathrm{mol} \mathrm{mm}-3$ & $5.08 \mathrm{E}-12$ \\
\hline $\begin{array}{l}\text { Oxygen limit for differentiation of carti- } \\
\text { lage to hypertrophic cartilage }\end{array}$ & $\mathrm{O}_{2}$ hypertrophic & \multicolumn{2}{|c|}{ Estimated } & $\mathrm{mol} \mathrm{mm}^{-3}$ & $30.48 \mathrm{E}-12$ \\
\hline $\begin{array}{l}\text { Oxygen limit for calcification of hyper- } \\
\text { trophic cartilage }\end{array}$ & $\mathrm{O}_{2}{ }^{\text {endochondral }}$ & \multicolumn{2}{|l|}{ Estimated } & $\mathrm{mol} \mathrm{mm}^{-3}$ & $50.48 \mathrm{E}-12$ \\
\hline Oxygen limit for inhibition of cartilage & $\mathrm{O}_{2}$ prolif & \multicolumn{2}{|c|}{ (Zhu et al, 2006) } & $\mathrm{mol} \mathrm{mm}^{-3}$ & $5.08 \mathrm{E}-12$ \\
\hline
\end{tabular}


adipogenesis. If none of these conditions were met then fibrogenesis occurred. FBs also had the capacity to transdifferentiate into OBs provided they met the conditions for osteogenesis i.e. high substrate stiffness and normoxic oxygen tension. Once an element had committed to a particular phenotype any remaining MSCs as well as any FBs in that element differentiated down that phenotypic pathway. An element was said to have committed to a particular phenotype if $50 \%$ of the total allowable lattice points within the element contained cells. Following this, the element was said to belong to the particular phenotype which made up the majority of cells. The model was updated to include a condition whereby MSC differentiation was inhibited in anoxic regions $\left(\mathrm{O}_{2} \leq \mathrm{O}_{2}{ }^{\text {death }}\right)$, this was based on experimental studies which have shown that severe hypoxia inhibits differentiation of MSCs (Cicione et al, 2013).

A simplified model of endochondral ossification was employed which split the process up into two main steps; initialisation of hypertrophy and; ossification. The initialisation step began when the newly differentiated CCs transformed into HCs. Based on the literature, this was assumed to occur when the local oxygen tension increased beyond a threshold value $\left(\mathrm{O}_{2}\right.$ hypertrophy $)$ (Sheehy et al, 2012; Leijten et al, 2014). The ossification step then characterised the process by which the newly transformed HCs recruit blood vessels and osteoprogenitor cells before undergoing apoptosis (Mackie et al. 2008) or transdifferentiating into OBs (Bahney et al, 2014). In the model, HCs were assumed to only do the latter and thus, provided that two condition were met HCs were converted directly into OBs. The first condition was that they had to be in the vicinity of an OB while the second condition was that the local oxygen tension had to be greater than a threshold value $\left(\mathrm{O}_{2}{ }^{\text {endochondral }}\right)$. The aim of the second condition was to mimic the behaviour of the invading blood vessels.

\subsection{Simulations}

Four different models were developed; one depicting normal fracture healing and three describing impaired vascularity which ranged from mild, moderate and severe. The models of impaired vascularity differed with respect to the boundary conditions used for their respective models of angiogenesis. In the mild simulation the angiogenic boundary conditions were assumed to return to the levels used in the normal fracture healing simulation at an earlier time point than they did for the moderate and severe simulations. Similarly, the moderate simulation was restored faster than the severe simulation. In each model, vessels could grow into the callus from the surrounding soft tissue, the marrow, the periosteum and endosteum of the cortical bone (Figure 2B). Simulations ran over a period of 28 days and each iteration represented a time step of 12 hours.
Normal Fracture Healing Initially, it was assumed that vessels could only grow into the callus from the periosteum of the cortical bone (Burke and Kelly, 2012; Burke et al, 2013; Geris et al, 2008; Chen et al, 2009; Carlier et al, 2015). 3 $\%$ of the lattice points on this edge contained active vessels. After 3 days, it was assumed that vessels could also perfuse into the upper callus from the surrounding soft tissue. $1 \%$ of the lattice points on this surface were considered to be active vessels in order to model the experimentally observed dominant vascular response from the cortical bone (Chen et al, 2009; Boerckel et al, 2011; Khayyeri et al, 2011). Due to the formation of the haematoma at the marrow and endosteum, vessel ingrowth from these surfaces was delayed until day 7.5 (Chen et al, 2009). The percentage of active vessels at these surfaces was taken to be $1 \%$ of the lattice points. Finally, as all of the surrounding surfaces were assumed to be vascularised, a constant oxygen tension of 50.48E-12 mol mm-3 (5\%) was implemented as a boundary condition at each of these surfaces from day 0 .

Mild Vascular Impairment On the cortical surface $0.3 \%$ of the lattice points became active vessels at day 0 and from day 5 this value increased linearly to $3 \%$ of the lattice points by day 8 . Similarly on the soft tissue surface $0.2 \%$ of the lattice points became active at day 2 and increased linearly from day 5 to $1 \%$ at day 8 . On the marrow surface $0.1 \%$ of the lattice points were active vessels at day 7.5 and this value increased linearly to $1 \%$ by day 10.5 .

Moderate Vascular Impairment Designed to be a transition between mild and severe ischemia, angiogenesis was not initiated in this model until day 6 . The number of active vessels then increased linearly with each time step on all the surfaces until it was fully recovered by day 9 .

Severe Vascular Impairment Blood vessel growth into the callus was not initiated until day 10 at which point the number of active vessels on each surface increased linearly from $0 \%$ to $3 \%$ on the periosteum surface, $0 \%$ to $1 \%$ on the soft tissue surface and $0 \%$ to $0.5 \%$ on the marrow surface by day 14 .

\section{Results}

\subsection{Normal Fracture Healing}

From day 0 to day 7, a dense vascular network was initiated at the periosteum and penetrated into the periosteal callus (Figure 3A). This led to an increase in the oxygen tension proximal to the cortical bone (Figure 3B). Similarly, as vessels invaded from the soft tissue at day 3 the oxygen tension in this region approached normoxic levels. By day 8 , only the cores of the external and internal calluses were 
Table 4 Cell Model Parameters

\begin{tabular}{|c|c|c|c|c|c|c|}
\hline Model Parameter & MSC & $\mathrm{CC}$ & FB & $\mathrm{OB}$ & $\mathrm{AB}$ & $\mathrm{HC}$ \\
\hline Doubling Time [days] & $0.5^{\mathrm{a}}$ & $1.5^{\mathrm{a}}$ & $0.5^{\mathrm{a}}$ & $1^{\mathrm{a}}$ & $0.5^{\mathrm{b}}$ & $1.5^{\mathrm{a}}$ \\
\hline Migration Rate $\left[\mu \mathrm{m} \mathrm{hr}^{-1}\right]$ & $26.6^{\mathrm{c}}$ & $\mathrm{N} \backslash \mathrm{A}$ & $26.6^{\mathrm{c}}$ & $\mathrm{N} \backslash \mathrm{A}$ & $26.6^{\mathrm{c}}$ & $\mathrm{N} \backslash \mathrm{A}$ \\
\hline $\begin{array}{l}\text { Anoxic Death Rate }[1 / 2 \\
\left.\text { day }^{-1}\right]\end{array}$ & 0.2 & 0.2 & 0.2 & 0.2 & 0.2 & 0.2 \\
\hline
\end{tabular}

Table 5 Oxygen consumption parameters of each cell phenotype

\begin{tabular}{|c|c|c|c|c|c|c|}
\hline $\begin{array}{l}\text { Michealas - Menten Coeffi- } \\
\text { cients }\end{array}$ & MSC & $\mathrm{CC}$ & FB & $\mathrm{OB}$ & $\mathrm{AB}$ & $\mathrm{HC}$ \\
\hline cell type (n) & 1 & 2 & 3 & 4 & 5 & 6 \\
\hline $\begin{array}{l}\text { Max Consumption Rate } \\
\left(\mathrm{Q}^{\max }\right)\left[\text { mol cell }{ }^{-1} \mathrm{hr}^{-1}\right]\end{array}$ & $98 \times 10^{-15 a, b}$ & $33 \times 10^{-15 a, b}$ & $98 \times 10^{-15 a, b}$ & $98 \times 10^{-15 a, b}$ & $98 \times 10^{-15 a, b}$ & $33 \times 10^{-15 a, b}$ \\
\hline $\begin{array}{l}\text { Oxygen Concentration at } \\
\text { half max consumption }\left(\mathrm{K}^{\mathrm{m}}\right) \\
{\left[\mathrm{mol} \mathrm{mm} \mathrm{mm}^{-3}\right]}\end{array}$ & $6 \times 10^{-12 \mathrm{c}, \mathrm{d}}$ & $6 \times 10^{-12 c, d}$ & $6 \times 10^{-12 c, d}$ & $6 \times 10^{-12 c, d}$ & $6 \times 10^{-12 c, d}$ & $6 \times 10^{-12 c, d}$ \\
\hline $\begin{array}{l}{ }^{a} \text { Burke et al (2013) } \\
\text { b Burke et al (2014) } \\
\text { c Pattappa et al (2011) } \\
\text { d Sengers et al (2005) }\end{array}$ & & & & & & \\
\hline
\end{tabular}

devoid of vessels. At this time, woven bone was predicted to form along the length of the periosteal cortex while fibrous tissue was observed adjacent to the soft tissue surface of the external callus. Chondrogenesis occurred in the cores of both the external and internal calluses and this large cartilage region bridged the fracture gap. Furthermore, at this stage, chondrocytes started to undergo hypertrophy around the peripheries of this cartilaginous region. By day 15, the fracture gap of the external callus was bridged by endochondral bone (Figure 3D) and by day 20 over $98 \%$ of the callus was bone. The remaining tissue was comprised of adipose tissue as well as a small region of hypertrophic cartilage located in the core of the internal callus.

At $10 \mathrm{dpf}$ the model was able to successfully predict the overall quantities of bone and cartilage observed experimentally (Figure 4A), as well as the spatial distribution of tissue phenotypes observed after histological staining of the fracture callus (Figure 4B). Furthermore, the prediction of the proportion of cartilage that was hypertrophic was similar to experimental observations at this timepoint (Figure 4C). In addition to this, the model prediction that the callus was almost entirely composed of bone at $20 \mathrm{dpf}$ matched the behaviour observed experimentally (data not shown).

\subsection{Fracture Healing with Impaired Angiogenesis}

In the model of mildly impaired angiogenesis, an anoxic environment was predicted throughout the entire callus at the early time points. By day 7, some necrotic tissue had formed in the medullary cavity. In the external callus the anoxic conditions supressed stem cell differentiation and hence the majority of this region remained as granulation tissue (Figure $5 \mathrm{~A}$ ). By day 10 , less than $10 \%$ of the callus volume consisted of new bone, while $40 \%$ of the callus consisted of cartilage or hypertrophic cartilage tissue (Figure 6A). By day 14 , in the external callus, as the blood supply began to recover, the necrotic tissue and any remaining granulation tissue was replaced by cartilage. As blood vessels penetrated further into the callus, so too did an advancing front of hypertrophic cartilage around the border of the cartilage tissue. In the region proximal to the cortical bone, the hypertrophic cartilage was followed by an osseous front formed via endochondral ossification. By day 28 , the callus had successfully bridged and was composed almost entirely of bone.

At $10 \mathrm{dpf}$ in the model of mildly impaired angiogenesis, $42 \%$ of the cartilage within the fracture callus was predicted to be hypertrophic (Figure 6B), which compares to $62 \%$ in the normal callus (Figure 4C). A persistence of cartilage was also predicted in the case of mildly impaired angiogenesis, with $15 \%$ of the callus consisting of cartilage at day 20 compared to less than $1 \%$ in the normal callus (data not shown). In the model of moderately impaired angiogenesis, the extended delay in vascularisation was predicted to result in an entirely different pattern of healing. Although blood vessels began to grow into the callus from day 6 , for the first two weeks following fracture the majority of the callus was comprised of necrotic tissue. By day 21 the internal callus consisted entirely of cartilage and hypertrophic cartilage. 
(A)

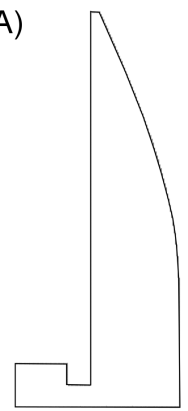

Day 0

(B)

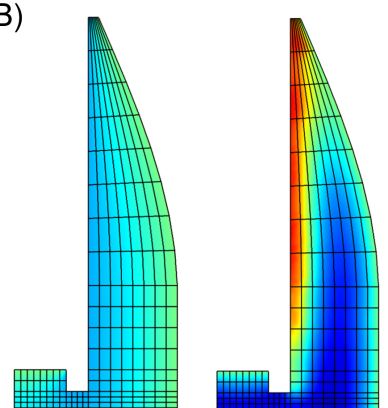

Day 0

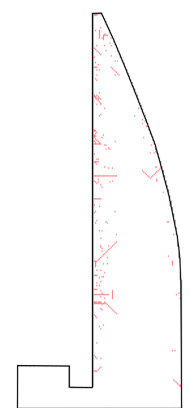

Day 5

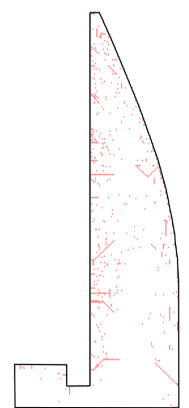

Day 10

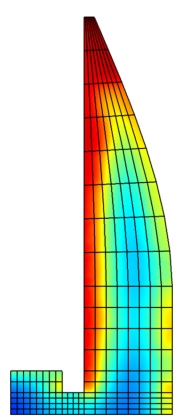

Day 10

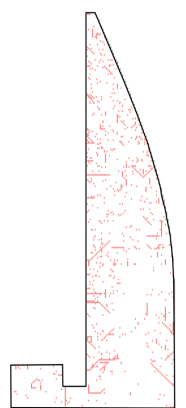

Day 15

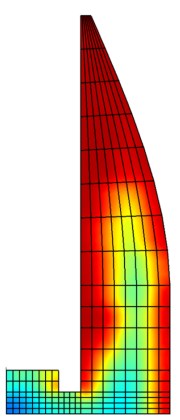

Day 15

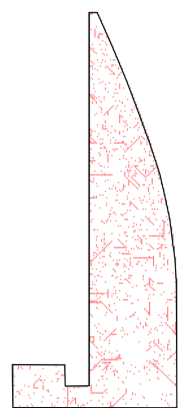

Day 20

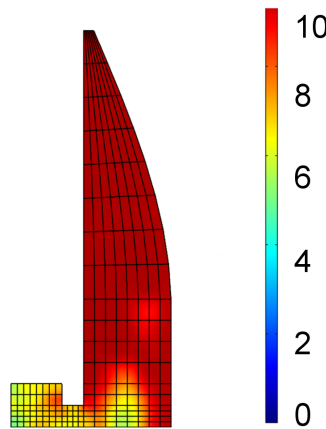

Day $20 \quad$ Oxygen

Tension [\%]

(C)

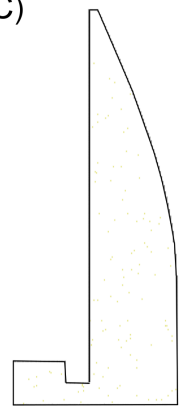

Day 0

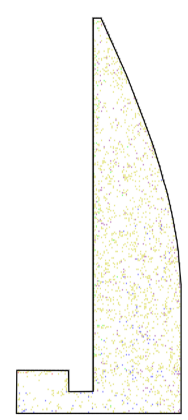

Day 5

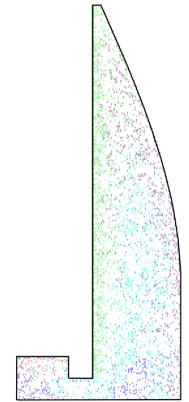

Day 10

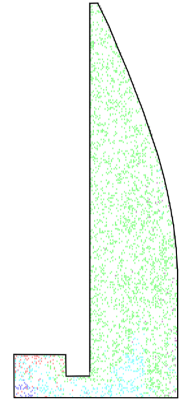

Day 15

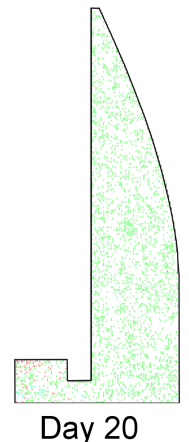

(D)

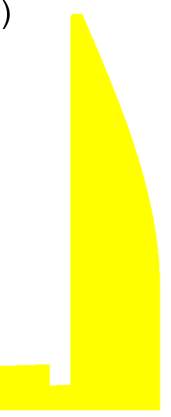

Day 0

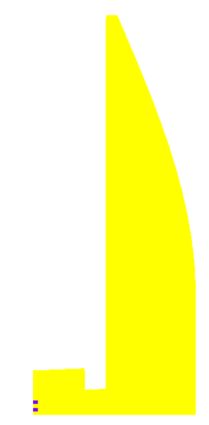

Day 5

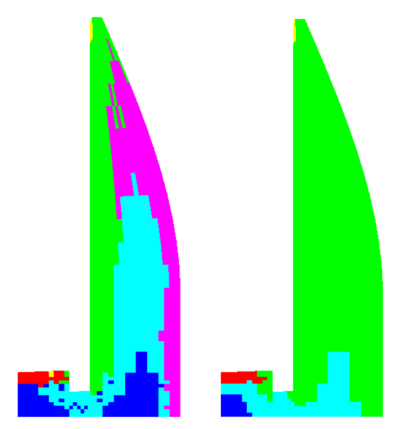

Day 15

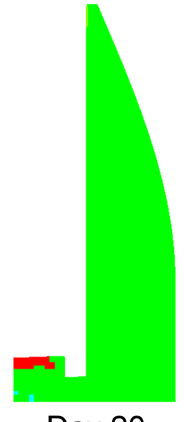

Day 20

\section{Granulation Tissue \\ Bone}

Adipose Tissue

Cartilage

Hypertrophic Cartilage

Fibrous Tissue

Fig. 3 Results from normal fracture healing at various time points: (A) Angiogenesis; (B) Oxygen Diffusion; (C) Cell Differentiation; (D) Tissue Phenotypes 
A)

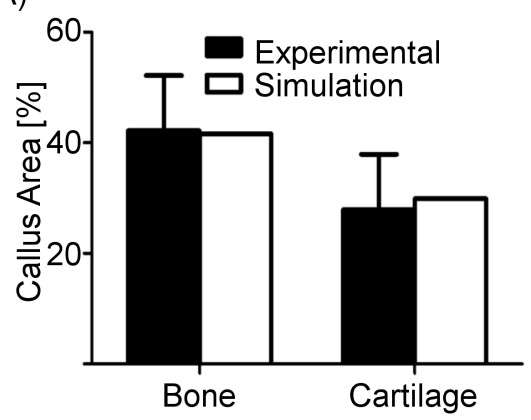

B)

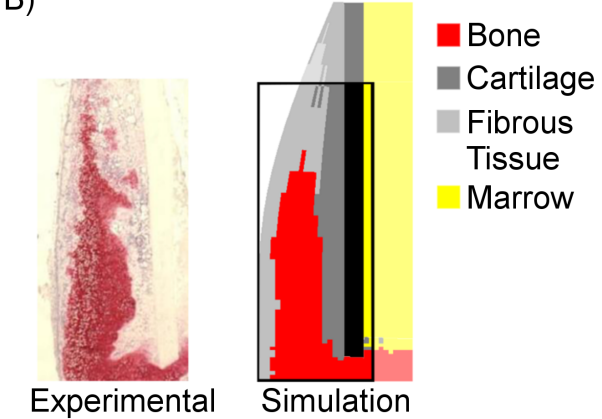

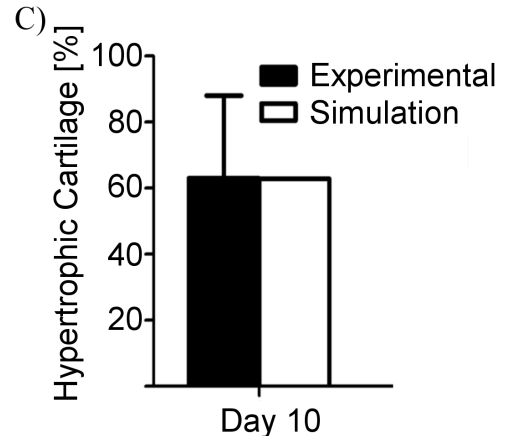

Fig. 4 (A) Experimental vs. Predicted percentages of callus area made up by cartilage and bone during normal fracture healing. (B) Safranin-O staining 10 days post fracture for normal fracture healing compared to model predictions for cartilage and bone formation. Both cartilage and hypertrophic cartilage are treated as the same material. (C) Experimental vs. Predicted percentage of cartilage tissue area which is hypertrophic in the normal fracture healing model at day 10.

Similarly the external callus was composed primarily of fibrous tissue on the soft tissue surface and woven bone which formed from the cortical surface. A cartilage region was also predicted to form in the core of the external callus. By day 28 the fracture gap had been bridged and the majority of the external callus had been replaced by bone. Throughout the entire healing process the maximum combined quantity of cartilage and hypertrophic cartilage never exceeded $20 \%$ of the total callus area.

A similar pattern of healing was predicted for the case of severely disrupted angiogenesis. For the first three weeks the majority of the callus area was comprised of necrotic tissue. By day 10 the number of live cells had decreased to a minimum value of less than $1 \%$ of the day 0 value (data not shown). The majority of the cellular activity occurred in the final week as MSCs continued to proliferate and started to differentiate. An osseous front of woven bone advanced from the cortical surface while the soft tissue surface was comprised mainly of fibrous tissue. Throughout the entire healing process, the combined quantity of cartilage and hypertrophic cartilage did not exceed $10 \%$ of the total callus area. By day 28 the fracture gap had not bridged and cartilage was present in the core of the external callus, the majority $(>70 \%$ ) of which was hypertrophic.

\section{Discussion}

The objective of this study was to use a computational mechanob ological model to provide a better understanding for how the altered microenvironment of an angiogenically impaired fracture callus, and in particular the altered levels of oxygen presented in such a regenerative scenario, regulates stem cell differentiation and tissue repair. In particular, we sought to test the hypothesis that the local oxygen tension regulates hypertrophy and endochondral ossification of the cartilage which forms in the callus of a fractured long bone. The first part of the study involved updating a previously de- veloped tissue differentiation algorithm (Burke and Kelly, 2012) to include a condition whereby the local oxygen levels regulate the initiation of chondrocyte hypertrophy and the progression of endochondral ossification. A second condition was also included to describe cell death and the suppression of MSC differentiation in regions of anoxia. The updated model and the underlying model hypotheses were then tested by simulating the time course of normal fracture healing in a murine tibia. The developed model was able to predict the main stages of the healing process, as well as the quantity and spatial distribution of tissue phenotypes (including the ratio of cartilage to hypertrophic cartilage) which were observed experimentally $10 \mathrm{dpf}$. Following this, the updated tissue differentiation algorithm was then used to simulate fracture healing under conditions of angiogenic impairment. These models were considered to represent different levels of ischemia, whereby it was assumed that ischemia arises as a result of delayed and reduced vascular ingrowth from the surrounding tissues.

In order to test the model hypothesis that oxygen levels regulate chondrocyte hypertrophy and endochondral ossification during fracture healing, model predictions were compared to experimental measurements of the ratio of cartilage to hypertrophic cartilage in normal and ischemic fractures (Taylor et al, 2009; Miedel et al, 2013). In the case of normal fracture healing, only the day 10 experimental results were available as very little cartilage was observed experimentally iby day 20 (Taylor et al, 2009). In both cases, the model was able to predict the correct ratio of cartilage to hypertrophic cartilage at day 10. In the ischemic model, the percentage of callus cartilage that was hypertrophic was predicted to increase between days 10 and 20. Such an increase was also observed experimentally, although not to the same extent as that predicted by the model. In addition, in the model of mildly impaired angiogenesis, the prediction of persistent cartilage in the fracture callus at day 20 is similar to that observed experimentally in GPCR kinase 2 interacting protein 
(A)

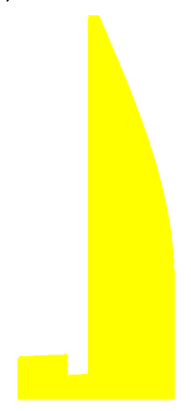

Day 0

B)

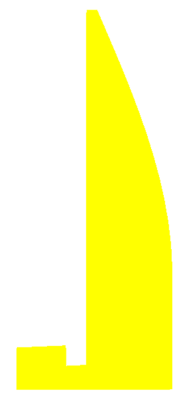

Day 0

C)

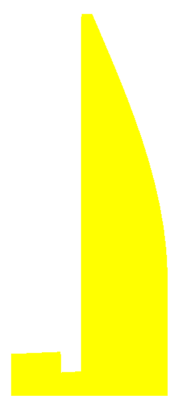

Day 0

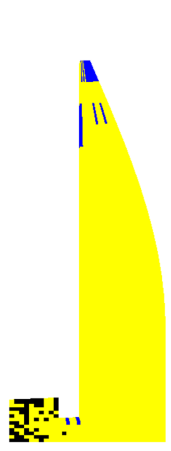

Day 7
Mild Ischemia

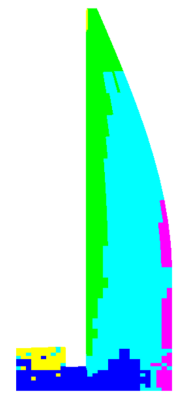

Day 14

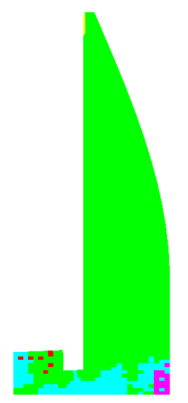

Day 21

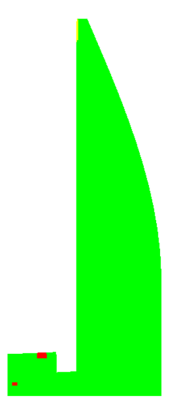

Day 28
Granulation Tissue

Bone

Adipose Tissue

Cartilage

Hypertrophic Cartilage

Fibrous Tissue

Necrotic Tissue

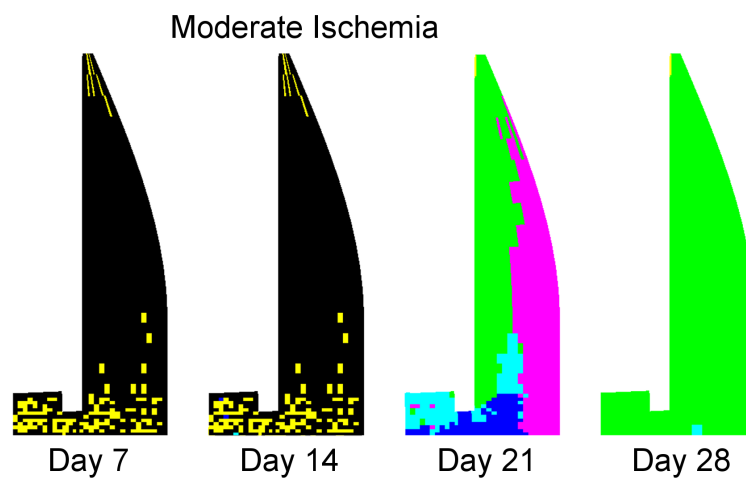

Day 28

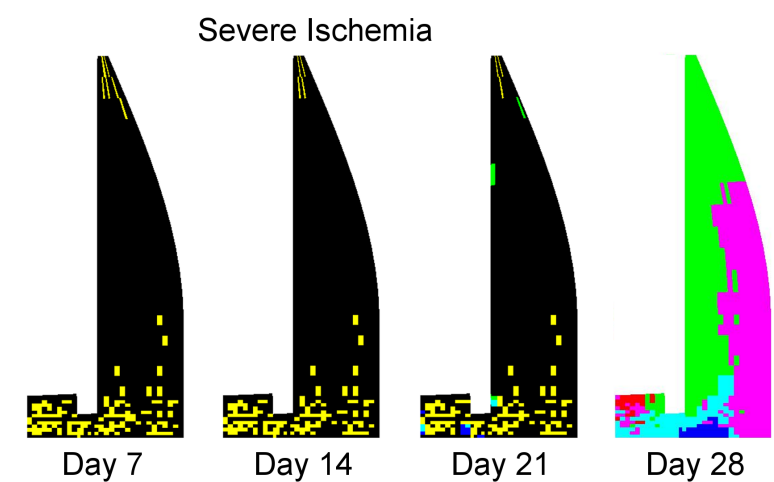

Fig. 5 Predicted tissue phenotypes from the impaired angiogenic fracture healing models: (A) Fracture healing during mild vascular impairment conditions: (B) Fracture healing during moderate vascular impairment conditions: (C) Fracture healing during severe vascular impairment conditions.

(GIT1) knock out mice (Yin et al, 2014). In that study, Yin et al. (Yin et al, 2014) reported that mice which were deficient in the gene GIT1 presented a reduction in both the density and the size of blood vessels within the callus during fracture healing of the tibia. This impaired vascularity resulted in a higher percentage of the callus area being composed of cartilage at day 21 when compared to the percentage calculated for wild type mice. This behaviour was also predicted within the model of mild vascular impairment when compared to the results of the model for normal fracture healing. These results provide support for the model hypothesis that endochondral ossification is initiated and regulated by the local oxygen concentration.

The developed models of ischemia also provide a potential explanation for the conflicting results reported by studies examining the pattern of healing within fractured ischemic limbs (Miedel et al, 2013; Lu et al, 2007). The predicted pattern of healing in the model of mildly impaired angiogenesis was similar to that observed experimentally during ischemic fracture healing by Miedel et al. (Miedel et al, 2013), while the pattern of healing predicted in the models of moderately and severely impaired angiogenesis was similar to the ex- 


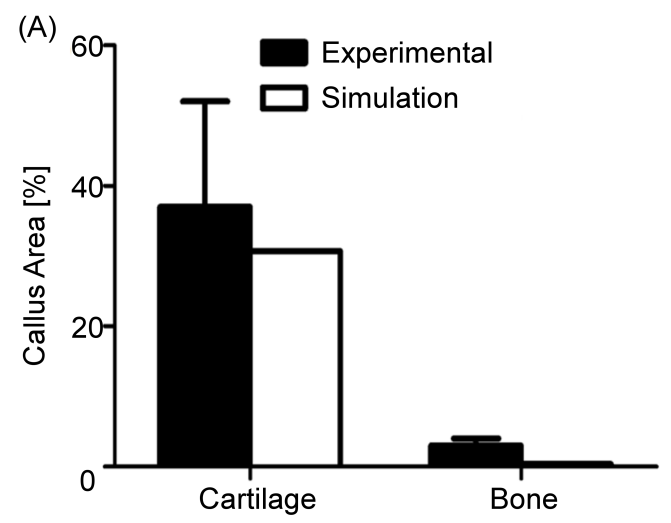

(B)

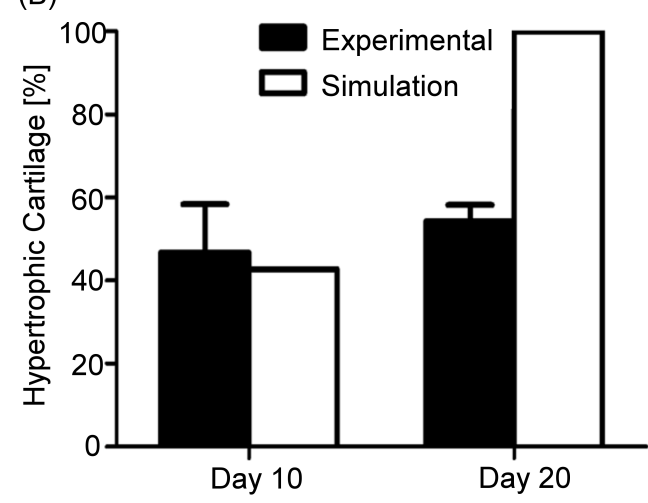

Fig. 6 (A) Percentages of callus area made up by cartilage and bone observed experimentally in the ischemic fracture healing model vs. the percentages predicted in the computational model of fracture healing during mild vascular impairment. (B) Percentage of cartilage tissue area which is hypertrophic observed experimentally in the model of ischemic fracture healing vs. the predicted percentages obtained from the computational model of fracture healing during mild vascular impairment.

perimental observations of Lu et al. (Lu et al, 2007). In their study, Miedel et al. (Miedel et al, 2013) found that, although ischemia during fracture healing resulted in delayed healing, by day 20, bony union between the cortical surfaces had been achieved. This behaviour was observed in the model of mild vascular impairment whereby bridging of the fracture gap had occurred by day 21 . In contrast, Lu et al. (Lu et al, 2007) reported that ischemic calluses contained no cartilage and did not achieve bony union by day 28 . This behaviour was predicted in the model of severely impaired angiogenesis where, following the initialisation of angiogenesis, the necrotic tissue was eventually replaced by fibrous tissue. By comparing our computational model predictions with experimental observations, it is postulated that experimentally observed differences in the outcome of fracture healing in these models of ischemia arise due to differences in the levels of trauma imposed on the vascular network. There were a number of limitations associated with the computational model which potentially impacted its predictive capacity. The model of angiogenesis, for example, did not consider the impact that gradients in growth factors within the callus might have had on blood vessel growth. In reality, the release of the growth factor VEGF by hypertrophic chondrocytes may play a key role in regulating angiogenesis during endochondral ossification (Keramaris et al, 2008). VEGF is a regulator of angiogenesis and has been linked with, among other features, the upregulation of vessel invasion into hypertrophic cartilage (Keramaris et al, 2008; Zelzer et al, 2004). This may provide an explanation for the over prediction of hypertrophic cartilage at day 20 in the model incorporating mildly impaired angiogenesis. To address this, a chemotaxis effect on blood vessel directionality should be implemented within the model framework in future studies.

There were a number of other limitations associated with this study, the first of which were related to the models of impaired vascularization. In general, ischemia tends to result in a smaller fracture callus compared to normal healing ( $\mathrm{Lu}$ et al, 2007; Miedel et al, 2013). This reduction in volume results in an altered mechanical environment in response to loading. The changes to the local strains may in turn lead to changes in the progression of angiogenesis and thus, differences in the local oxygen environment. Despite this, alterations in the callus geometry due to impaired angiogenesis were not considered and as such, the same geometry was used for both the normal and impaired angiogenesis fracture models. This basis of this simplification was the assumption that delayed vascularity, rather than an altered initial mechanical environment, was the main mechanism by which impaired angiogenesis affected progenitor cell fate.

The remaining limitations of the models are the same as the ones previously outlined by Burke et al. (Burke et al, 2013). These were: 1) An idealised axisymmetric model of the callus was employed which assumed that the medial and lateral sides of the callus were identical: 2) An assumption that the intramedullary pin provided complete lateral stability and the applied splints provided full torsional stability, hence only axial loading was considered: 3) Simplified representations of complex in-vivo processes were used to model cell proliferation and migration, angiogenesis and oxygen transport: 4) Simplified biphasic material models were used, which ignored the complex viscoelastic nature of the solid constituents of the regenerating soft tissue. In all cases, the effect of each of these simplifications was considered to be sufficiently small so as not to significantly reduce the predictive capacity of the developed models.

In spite of these limitations the updated algorithm used in this study was able to predict the pattern of healing seen in both normal and ischemic fracture repair. Based on the developed models, it was also possible to elucidate a mechanism to potentially explain variations in bone regeneration observed in different experimental models of ischemic frac- 
ture repair. Furthermore, the models provided additional evidence for the hypothesis that hypertrophy of chondrocytes in-vivo during regenerative events such as fracture healing is regulated by the local oxygen availability. Future work will involve using the algorithm to model other tissue differentiation events such as osteochondral defects. This will allow for further validation and improvement of the developed algorithm. It will also provide a means to better understand how the local microenvironment regulates stem cell fate during tissue regeneration.

Acknowledgements Funding provided by a European Research Council Starter Grant (StemRepair No. 258463).

\section{References}

Alierta Ja, Pérez Ma, García-Aznar JM (2014) An interface finite element model can be used to predict healing outcome of bone fractures. Journal of the Mechanical Behavior of Biomedical Materials 29:328-338, DOI 10.1016/j.jmbbm.2013.09.023

Appeddu PA, Shur BD (1994) Molecular analysis of cell surface fi-1 , 4-galactosyltransferase function during cell migration. Proceedings of the National Academy of Sciences of the United States of America 91(March):20952099

Bahney C, Hu D, Ferro F, Taylor A, Miclau T, Marcucio R (2014) Transdifferentiation of hypertrophic chondrocytes during endochondral bone repair by activation of pluripotent stem cell programs (216.1). The Journal of the Federation of American Societies for Experimental Biology 28(1)

Boerckel JD, Uhrig Ba, Willett NJ, Huebsch N, Guldberg RE (2011) Mechanical regulation of vascular growth and tissue regeneration in vivo. Proceedings of the National Academy of Sciences of the United States of America 108(37):E674-80, DOI 10.1073/pnas.1107019108, URL http://www.pubmedcentral.nih.gov/ articlerender.fcgi?artid=3174614 $\backslash$ \&tool= pmcentrez \\&rendertype=abstract

Brinker, Mark R M, Bailey, Daniel E Jr M (1997) Fracture Healing in Tibia Fractures with an Associated Vascular Injury . Fracture Healing in Tibia Fractures with an Associated Vascular Injury Ovid : Fracture Healing in Tibia Fractures with an Associated Vascular Injury. The Journal of Trauma: Injury, Infection, and Critical Care 42(1):11-19

Burke D, Dishowitz M, Sweetwyne M, Miedel E, Hankenson KD, Kelly DJ (2013) The role of oxygen as a regulator of stem cell fate during fracture repair in TSP2-null mice. Journal of orthopaedic research : official publication of the Orthopaedic Research Society 31(10):1585-
96, DOI 10.1002/jor.22396, URL http://www.ncbi. nlm.nih.gov/pubmed/23775935

Burke DP (2013) An investigation into the role of substrate stiffness and oxygen availability in the regulation of stem cell differentiation during tissue regeneration. $\mathrm{PhD}$ thesis, Trinity College Dublin

Burke DP, Kelly DJ (2012) Substrate stiffness and oxygen as regulators of stem cell differentiation during skeletal tissue regeneration: a mechanobiological model. PloS one 7(7):e40,737, DOI 10.1371/journal.pone.0040737, URL http://www.pubmedcentral.nih.gov/ articlerender.fcgi?artid=3404068\\&tool= pmcentrez \\&rendertype=abstract

Burke DP, Khayyeri H, Kelly DJ (2014) Substrate stiffness and oxygen availability as regulators of mesenchymal stem cell differentiation within a mechanically loaded bone chamber. Biomechanics and modeling in mechanobiology DOI 10.1007/s10237-014-0591-7, URL http://www.ncbi.nlm.nih.gov/pubmed/24832965

Cao Y (2007) Angiogenesis modulates adipogenesis and obesity. Science in medicine 117(9), DOI 10.1172/ JCI32239.2362

Carlier A, Geris L, Gastel NV, Carmeliet G, Oosterwyck HV (2015) Oxygen as a critical determinant of bone fracture healing A multiscale model. Journal of Theoretical Biology 365:247-264, DOI 10.1016/j.jtbi.2014. 10.012, URL http://dx.doi.org/10.1016/j.jtbi. 2014.10.012

Checa S, Prendergast PJ (2009) A mechanobiological model for tissue differentiation that includes angiogenesis: a lattice-based modeling approach. Annals of biomedical engineering 37(1):129-45, DOI 10.1007/s10439-008-9594-9, URL http://www.ncbi. nlm.nih.gov/pubmed/19011968

Chen G, Niemeyer F, Wehner T, Simon U, Schuetz Ma, Pearcy MJ, Claes LE (2009) Simulation of the nutrient supply in fracture healing. Journal of biomechanics 42(15):2575-83, DOI 10.1016/j.jbiomech.2009.07. 010, URL http://www.ncbi.nlm.nih.gov/pubmed/ 19660757

Cicione C, Muinos-Lopez E, Hermida-Gomez T, FuentesBoquete I, Diaz-Prado S, Blanco FJ (2013) Effects of severe hypoxia on bone marrow mesenchymal stem cells differentiation potential. Stem cells international 2013:232,896, DOI 10.1155/2013/232896, URL http://www.pubmedcentral.nih.gov/ articlerender.fcgi?artid=3777136 $\backslash \&$ tool= pmcentrez \\&rendertype=abstract

Claes LE, Heigele Ca, Neidlinger-Wilke C, Kaspar D, Seidl W, Margevicius KJ, Augat P (1998) Effects of mechanical factors on the fracture healing process. Clinical orthopaedics and related research (355 Suppl):S13247, URL http://www.ncbi.nlm.nih.gov/pubmed/ 


\section{4}

Engler AJ, Sen S, Sweeney HL, Discher DE (2006) Matrix elasticity directs stem cell lineage specification. Cell 126(4):677-89, DOI 10.1016/j.cell.2006.06.044, URL http://www.ncbi.nlm.nih.gov/pubmed/16923388

Epari DR, Lienau J, Schell H, Witt F, Duda GN (2008) Pressure, oxygen tension and temperature in the periosteal callus during bone healing-an in vivo study in sheep. Bone 43(4):734-9, DOI 10.1016/j.bone.2008.06. 007, URL http://www.ncbi.nlm.nih.gov/pubmed/ 18634913

Gawlitta D, van Rijen M, Schrijver E, Alblas J, Dhert W (2012) Hypoxia Impedes Hypertrophic Chondrogenesis of Human Multipotent Stromal Cells. Tissue Engineering Part A 18(19-20):1957-1966

Geris L, Gerisch A, Sloten JV, Weiner R, Oosterwyck HV (2008) Angiogenesis in bone fracture healing: a bioregulatory model. Journal of theoretical biology 251(1):13758, DOI 10.1016/j.jtbi.2007.11.008, URL http: //www . ncbi.nlm.nih.gov/pubmed/18155732

Gomillion CT, Burg KJL (2006) Stem cells and adipose tissue engineering. Biomaterials 27(36):6052-63, DOI 10.1016/j.biomaterials.2006.07.033, URL http: //www . ncbi.nlm.nih.gov/pubmed/16973213

Hankenson KD, Dishowitz M, Gray C, Schenker M (2011) Angiogenesis in bone regeneration. Injury 42(6):556-61, DOI 10.1016/j.injury.2011.03.035, URL http://www.pubmedcentral.nih.gov/ articlerender.fcgi?artid=3105195\\&tool= pmcentrez \\&rendertype=abstract

Hausman GJ, Richardson RL (2004) Adipose tissue angiogenesis. Journal of Animal Science 82:925-934

Hershey D, Karhan T (1968) Diffusion Coefficients for Oxygen Transport in Whole Blood. AIChE 14(6):969-972

Hirao M, Tamai N, Tsumaki N, Yoshikawa H, Myoui A (2006) Oxygen tension regulates chondrocyte differentiation and function during endochondral ossification. The Journal of biological chemistry 281(41):31,07992, DOI 10.1074/jbc.M602296200, URL http://www . ncbi.nlm.nih.gov/pubmed/16905540

Hori RY, Lewis JL (1982) Mechanical properties of the fibrous tissue found at the bone-cement interface following total joint replacement. Journal of biomedical materials research 16(6):911-27, DOI 10.1002/jbm. 820160615, URL http://www.ncbi.nlm.nih.gov/ pubmed/7174716

Huebsch N, Arany PR, Mao AS, Shvartsman D, Ali Oa, Bencherif Sa, Rivera-Feliciano J, Mooney DJ (2010) Harnessing traction-mediated manipulation of the cell/matrix interface to control stem-cell fate. Nature materials 9(6):518-26, DOI 10.1038/nmat2732, URL http://www.pubmedcentral.nih.gov/ articlerender.fcgi?artid=2919753 \\&tool= pmcentrez \\&rendertype=abstract

Isaksson H, van Donkelaar CC, Huiskes R, Ito K (2008) A mechano-regulatory bone-healing model incorporating cell-phenotype specific activity. Journal of theoretical biology 252(2):230-46, DOI 10.1016/j.jtbi.2008.01. 030, URL http://www.ncbi.nlm.nih.gov/pubmed/ 18353374

Kanichai M, Ferguson D, Prendergast PJ, Campbell Va (2008) Hypoxia promotes chondrogenesis in rat mesenchymal stem cells: a role for AKT and hypoxiainducible factor (HIF)-1alpha. Journal of cellular physiology 216(3):708-15, DOI 10.1002/jcp.21446, URL http: //www.ncbi.nlm.nih.gov/pubmed/18366089

Keramaris NC, Calori GM, Nikolaou VS, Schemitsch EH, Giannoudis PV (2008) Fracture vascularity and bone healing: a systematic review of the role of VEGF. Injury 39 Suppl 2:S4557, DOI 10.1016/S0020-1383(08)70015-9, URL http://www.ncbi.nlm.nih.gov/pubmed/18804573

Khayyeri H, Checa S, Tägil M, Aspenberg P, Prendergast PJ (2011) Variability observed in mechano-regulated in vivo tissue differentiation can be explained by variation in cell mechano-sensitivity. Journal of biomechanics 44(6):1051-8, DOI 10.1016/j.jbiomech.2011.02. 003, URL http://www.ncbi.nlm.nih.gov/pubmed/ 21377680

Lacroix D, Prendergast PJ (2002) A mechano-regulation model for tissue differentiation during fracture healing: analysis of gap size and loading. Journal of biomechanics 35(9):1163-71, URL http://www.ncbi.nlm.nih. gov/pubmed/12163306

Lacroix D, Prendergast PJ, Li G, Marsh D (2002) Biomechanical model to simulate tissue differentiation and bone regeneration: application to fracture healing. Medical \& biological engineering \& computing 40(1):14-21, URL http://www.ncbi.nlm.nih.gov/pubmed/11954702

Leijten J, Georgi N, Moreira Teixeira L, van Blitterswijk Ca, Post JN, Karperien M (2014) Metabolic programming of mesenchymal stromal cells by oxygen tension directs chondrogenic cell fate. Proceedings of the National Academy of Sciences of the United States of America DOI 10.1073/pnas.1410977111, URL http: //www . ncbi.nlm.nih.gov/pubmed/25205812

Leijten JCH, Moreira Teixeira LS, Landman EBM, van Blitterswijk Ca, Karperien M (2012) Hypoxia inhibits hypertrophic differentiation and endochondral ossification in explanted tibiae. PloS one 7(11):e49,896, DOI 10.1371/journal.pone.0049896, URL http://www.pubmedcentral.nih.gov/ articlerender.fcgi? artid=3503827 $\backslash \&$ tool= pmcentrez $\backslash$ \&rendertype=abstract

Lu C, Miclau T, Hu D, Marcucio RS, Al LUET (2007) Ischemia Leads to Delayed Union during Fracture Heal- 
ing : A Mouse Model. Journal of orthopaedic research : official publication of the Orthopaedic Research Society 25(1):51-61, DOI 10.1002/jor

Miedel E, Dishowitz MI, Myers MH, Dopkin D, Yu YY, Miclau TS, Marcucio R, Ahn J, Hankenson KD (2013) Disruption of thrombospondin-2 accelerates ischemic fracture healing. Journal of orthopaedic research : official publication of the Orthopaedic Research Society 31(6):935-43, DOI 10.1002/jor.22302, URL http:// www.ncbi.nlm.nih.gov/pubmed/23280580

Park JS, Chu JS, Tsou AD, Diop R, Tang Z, Wang A, Li S (2011) The effect of matrix stiffness on the differentiation of mesenchymal stem cells in response to TGF- $\beta$. Biomaterials 32(16):392130, DOI 10.1016/j.biomaterials.2011.02.019, URL http://www.pubmedcentral.nih.gov/ articlerender.fcgi?artid=3073995 \\&tool= pmcentrez \\&rendertype=abstract

Pattappa G, Heywood HK, de Bruijn JD, Lee Da (2011) The metabolism of human mesenchymal stem cells during proliferation and differentiation. Journal of cellular physiology 226(10):2562-70, DOI 10.1002/jcp.22605, URL http://www.ncbi.nlm.nih.gov/pubmed/21792913

Peiffer V, Gerisch A, Vandepitte D, Van Oosterwyck H, Geris L (2011) A hybrid bioregulatory model of angiogenesis during bone fracture healing. Biomechanics and modeling in mechanobiology 10(3):383-95, DOI 10.1007/s10237-010-0241-7, URL http://www.ncbi. nlm.nih.gov/pubmed/20827500

Pérez Ma, Prendergast PJ (2007) Random-walk models of cell dispersal included in mechanobiological simulations of tissue differentiation. Journal of biomechanics 40(10):2244-53, DOI 10.1016/j.jbiomech.2006.10. 020, URL http://www.ncbi.nlm.nih.gov/pubmed/ 17173925

Prasad J, Wiater BP, Nork SE, Bain SD, Gross TS (2010) Characterizing gait induced normal strains in a murine tibia cortical bone defect model. Journal of biomechanics 43(14):2765-70, DOI 10.1016/j.jbiomech.2010.06. 030, URL http://www.ncbi.nlm.nih.gov/pubmed/ 20674920

Sengers BG, van Donkelaar CC, Oomens CWJ, Baaijens FPT (2005) Computational study of culture conditions and nutrient supply in cartilage tissue engineering. Biotechnology progress 21(4):1252-61, DOI 10. 1021/bp0500157, URL http://www.ncbi.nlm.nih. gov/pubmed/16080709

Sheehy EJ, Buckley CT, Kelly DJ (2012) Oxygen tension regulates the osteogenic, chondrogenic and endochondral phenotype of bone marrow derived mesenchymal stem cells. Biochemical and biophysical research communications 417(1):305-10, DOI 10.1016/j.bbrc.2011.11. 105, URL http://www.ncbi.nlm.nih.gov/pubmed/
22155244

Street J, Bao M, DeGuzman L, Bunting S, Peale FV, Ferrara N, Steinmetz H, Hoeffel J, Cleland JL, Daugherty A, van Bruggen N, Redmond HP, Carano RaD, Filvaroff EH (2002) Vascular endothelial growth factor stimulates bone repair by promoting angiogenesis and bone turnover. Proceedings of the National Academy of Sciences of the United States of America 99(15):9656-61, DOI 10.1073/pnas.152324099, URL http://www.pubmedcentral.nih.gov/ articlerender.fcgi?artid=124965 \&\&tool= pmcentrez $\backslash$ \&rendertype=abstract

Taylor DK, Meganck JA, Terkhorn S, Rajani R, Naik A, Keefe RJO, Goldstein SA, Hankenson KD (2009) Thrombospondin-2 Influences the Proportion of Cartilage and Bone During Fracture Healing. Journal of bone and mineral research : the official journal of the American Society for Bone and Mineral Research 24(6):1043-1054, DOI 10.1359/JBMR.090101

Yin G, Sheu TJ, Menon P, Pang J, Ho HC, Shi S, Xie C, Smolock E, Yan C, Zuscik MJ, Berk BC (2014) Impaired angiogenesis during fracture healing in GPCR kinase 2 interacting protein-1 (GIT1) knock out mice. PloS one 9(2):e89,127, DOI 10.1371/journal.pone.0089127, URL http://www.pubmedcentral.nih.gov/ articlerender.fcgi?artid=3929643\\&tool= pmcentrez $\backslash$ \&rendertype=abstract

Young DA, Choi YS, Engler AJ, Christman KL (2013) Stimulation of adipogenesis of adult adipose-derived stem cells using substrates that mimic the stiffness of adipose tissue. Biomaterials 34(34):8581-8, DOI 10.1016/j.biomaterials.2013.07.103, URL http://www . ncbi.nlm.nih.gov/pubmed/23953825

Zelzer E, Mamluk R, Ferrara N, Johnson RS, Schipani $\mathrm{E}$, Olsen BR (2004) VEGFA is necessary for chondrocyte survival during bone development. Development (Cambridge, England) 131(9):2161-71, DOI 10.1242/dev.01053, URL http: //www.ncbi.nlm.nih. gov/pubmed/15073147

Zhu M, Feng Q, Bian L (2014) Differential effect of hypoxia on human mesenchymal stem cell chondrogenesis and hypertrophy in hyaluronic acid hydrogels. Acta biomaterialia 10(3):1333-40, DOI 10.1016/j.actbio.2013.12. 015, URL http://www.ncbi.nlm.nih.gov/pubmed/ 24342044

Zhu W, Chen J, Cong, Xiangfeng M, Hu S, Chen, Xi PD (2006) Hypoxia and Serum Deprivation-Induced Apoptosis in Mesenchymal Stem Cells. Stem Cells 24(2):416425, DOI 10.1634/stemcells.2005-0121 